\title{
Intrahippocampal muscimol shifts learning strategy in gonadally intact young adult female rats
}

\author{
Molly W. McElroy ${ }^{1}$ and Donna L. Korol ${ }^{1,2,3}$ \\ ${ }^{1}$ Neuroscience Program and ${ }^{2}$ Department of Psychology, University of Illinois, Urbana-Champaign, \\ Champaign, Illinois 61820, USA
}

\begin{abstract}
Learning strategy preferences depend upon circulating estrogen levels, with enhanced hippocampus-sensitive place learning coinciding with elevated estrogen levels. The effects of estrogen on strategy may be mediated by fluctuations in GABAergic function, given that inhibitory tone in the hippocampus is low when estrogen is high. We investigated the effects on learning strategy of intrahippocampal injections of a $\mathrm{GABA}_{\mathrm{A}}$ agonist in gonadally intact female rats. On the day of training, rats received $0.3 \mu \mathrm{L}$ intrahippocampal infusions of muscimol $(0.26 \mathrm{nmol}$ or 2.6 nmol) or saline $20 \mathrm{~min}$ prior to training on a T-maze in which place (hippocampus-sensitive) or response (striatum-sensitive) strategies offer effective solutions. Muscimol treatment increased the use of the response strategy in a dose-dependent manner without influencing learning speed, indicating that muscimol modulated strategy and not learning ability. Furthermore, the muscimol-related shift to response strategies varied across the estrous cycle. The results indicate that increasing inhibition in the hippocampus biases rats away from hippocampus-sensitive place learning strategies and toward hippocampus-insensitive response learning strategies without a learning deficit. Furthermore, rats at proestrus demonstrated the most dramatic shift in learning strategy following muscimol treatment compared with control conditions, while rats at estrus demonstrated the most complete bias toward response strategies. The enhanced use of hippocampus-sensitive strategies at proestrus likely results from reduced hippocampal inhibition.
\end{abstract}

The effects of reproductive hormones on cognition are not well understood. Studies have found that estrogen can both improve (Daniel et al. 1997; Packard and Teather 1997; Fader et al. 1998; Gibbs et al. 1998, 2004; Bimonte and Denenberg 1999; Daniel and Dohanich 2001; Luine et al. 2003) and impair (Frye 1995; Galea et al. 1995, 2002; Warren and Juraska 1997; Chesler and Juraska 2000) learning and memory depending upon the type of task and hormone exposure regimen (for review, see Dohanich 2002).

We have consistently found that estrogen influences the learning strategy used to solve a task (Korol and Manning 2001; Korol and Kolo 2002; Korol et al. 2004). For example, female rats with endogenously (Korol et al. 2004) or exogenously (Thomas et al. 2001) high levels of estrogen tend to choose the hippocampus-sensitive place strategy in a T-maze task that can be solved with either a place or response (striatum-sensitive) strategy. Likewise, female rats administered acute treatments of estrogen reached criterion in a place version of a four-arm radial maze faster than in a response version of the task (Korol and Kolo 2002). Conversely, compared with those with high circulating estrogen, female rats with low estrogen profiles tend to be more efficient at solving response tasks and tend to choose response strategies over other equally effective solutions (Thomas et al. 2001; Korol and Kolo 2002; Korol et al. 2004). In a swim task, estrogen-deprived female rats were more efficient in solving a spatial task in which the goal location was marked with a static cue (Daniel and Lee 2004), a task that likely taps nonhippocampal systems such as the striatum (Pearce et al. 1998; White and McDonald 2002).

From the view of multiple memory systems, estrogen may influence learning strategy by shifting the relative contribution

\footnotetext{
${ }^{3}$ Corresponding author.

E-mail dkorol@uiuc.edu; fax (217) 244-5876.

Article and publication are at http://www.learnmem.org/cgi/doi/10.1101/ Im.86205.
}

of neural systems involved in learning and memory. A variety of studies using surgical (McDonald and White 1993; Moser et al 1993; Steffenach et al. 2002) and temporary pharmacological (Packard and McGaugh 1996; Moser and Moser 1998a; Schroeder et al. 2002; Chang and Gold 2003a) lesions show that the hippocampus is important for place learning (for reviews, see White and McDonald 2002; Holscher 2003; Poldrack and Packard 2003). Hippocampal inactivation through the infusion of the $\gamma$-amino butyric acid $(\mathrm{GABA})_{\mathrm{A}}$ agonist muscimol into the dorsal hippocampus also causes impairment on a variety of hippocampus-dependent tasks, including place learning (Mao and Robinson 1998; Moser and Moser 1998a; Vianna et al. 2000; Corcoran and Maren 2001; Maruki et al 2001; Rossato et al. 2004). Consistent with these findings, enhancements of hippocampussensitive behaviors such as place learning and spontaneous alternation (Johnson et al. 1977; Mickley et al. 1989; Walker and Gold 1994; for review, see Lalonde 2002) are found following infusions of glutamate (Packard 1999) and glucose (Ragozzino et al. 1998) into the hippocampus. It is possible that the improved place learning observed when estrogen levels are high results from estrogen-mediated increases in hippocampal function.

Accumulating evidence suggests that estrogen heightens hippocampal excitability through the suppression of inhibition. Many of the estrogen receptor-positive cells in the hippocampus are also immunoreactive for GABA in the hippocampus Hart et al. 2001; Su et al. 2001). The application of estrogen to cultured hippocampal interneurons decreases glutamate decarboxylase (GAD; the GABA synthesizing enzyme) content by as much as $80 \%$ (Murphy et al. 1998). Similarly, in vivo estrogen administration to ovariectomized rats decreases inhibitory currents and the number of GAD+ cells measured in the hippocampus (Rudick and Woolley 2001). Together, these results indicate that GABAergic cells are estrogen sensitive and that estrogen may change hippocampal function by decreasing inhibition through GABAergic mechanisms. 


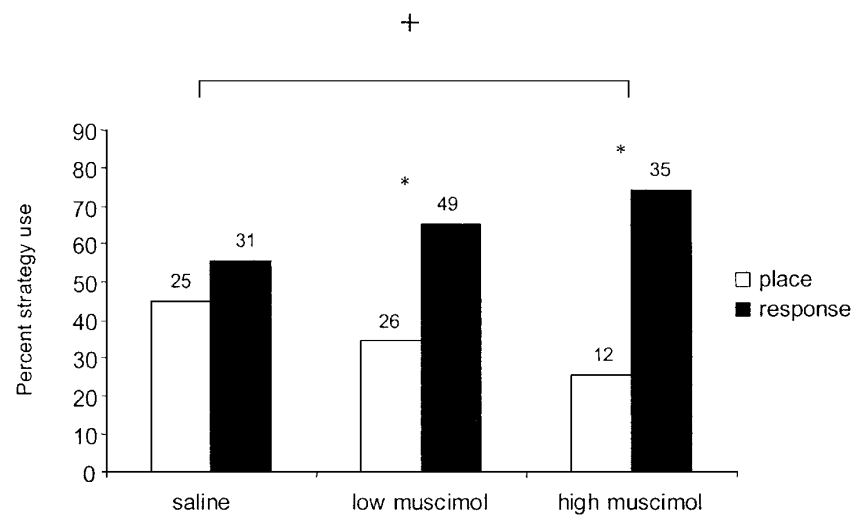

Figure 1. Proportion of strategy use following muscimol treatment regardless of estrous cycle stage. Intrahippocampal injections of muscimol shifted learning strategy to a response strategy in a dose-dependent manner, although both low $(0.26 \mathrm{nmol})$ and high $(2.6 \mathrm{nmol})$ doses produced significant strategy biases. Rats treated with the high muscimol dose used the response strategy more often than did saline-treated rats. The numbers above each bar indicate the $N$ for each group. ${ }^{*} P<0.05$ within group; $+P<0.05$ relative to saline controls.

Given that enhanced GABAergic function in the dorsal hippocampus impairs place learning (Moser and Moser 1998a; Mao and Robinson 1998) and that hippocampal GABAergic activity fluctuates in response to estrogen (Murphy et al. 1998; Rudick and Woolley 2001), it is likely that up- and down-regulation of GABA contributes to the shifts in learning strategy we have observed across the estrous cycle. To test this idea, we investigated the effects of intrahippocampal muscimol, a selective $\mathrm{GABA}_{\mathrm{A}}$ agonist, on learning strategy in gonadally intact young female rats. Rats received bilateral intrahippocampal infusions of muscimol prior to training on a dual solution T-maze that could be solved with either a place or a response strategy. We hypothesized that muscimol would shift the population of rats toward using a response learning strategy. Based on findings that endogenous GABAergic activity fluctuates according to estrogen levels (Murphy et al. 1998; Rudick and Woolley 2001) and the extensive literature showing that progesterone metabolites, such as allopregnanolone, enhance agonist binding to the $\mathrm{GABA}_{\mathrm{A}}$ receptor (Gee 1988; Turner et al. 1989; for review, see Kawata 1995), we also hypothesized that the magnitude of the strategy shift to response would vary across the estrous cycle. Because both inhibitory tone and binding properties of $\mathrm{GABA}_{\mathrm{A}}$ agonists in the hippocampus change across the estrous cycle, the efficacy of muscimol to induce a strategy shift may differ according to estrous stage. Briefly, we found that hippocampal muscimol infusions led to the use of response strategies, producing a shift in cognitive approach that was more obvious in proestrous rats.

\section{Results}

\section{Effects of treatments on strategy use}

\section{General muscimol effects}

Intrahippocampal infusions of muscimol produced a dramatic bias in strategy use, with the majority of muscimol-treated rats using a response strategy (Fig. 1). Specifically, in saline-treated rats $(n=56), 45 \%$ used a place strategy and 55\% used a response strategy regardless of estrous cycle phase. In contrast, treatment with the low muscimol dose $(n=75)$ caused a strategy bias $(z=2.54, P<0.05)$, with $35 \%$ of the rats using a place strategy and $65 \%$ a response strategy, while treatment with the high muscimol dose $(n=47)$ produced a significant strategy bias $(z=6.10$,
$P<0.05)$, with $26 \%$ of the rats using a place strategy and $74 \%$ a response strategy. A $\chi^{2}$ analysis that compared strategy use across the different treatments revealed a significant difference in strategy use between saline and the high muscimol dose $\left(\chi_{[1,102]}^{2}=4.01\right.$, $P<0.05)$. However, rats treated with the low dose of muscimol did not show differences in learning strategy compared with the saline-treated group $\left(\chi_{[1,130]}^{2}=1.34, P>0.05\right)$ or the high muscimol-treated group $\left(\chi_{[1,121]}^{2}=1.12, P>0.05\right)$.

\section{Estrous cycle interactions}

As expected from our previous work (Korol et al. 2004), salinetreated control rats showed differences in strategy use between stages of the estrous cycle (Fig. 2, top panel). Note that data are represented with proestrus followed by diestrus and then estrus, in place of the natural order of the cycle (i.e., proestrus, estrus, then diestrus) to reflect relatively descending levels of circulating hormones.

Saline-treated proestrous rats, with high ovarian hormone profiles, used place strategies more than response strategies $(67 \%$ versus $33 \%$, respectively). Estrous rats with low ovarian hormone profiles predominantly used response strategies more than place strategies ( $72 \%$ versus $28 \%$, respectively), a behavior pattern opposite that of proestrous rats. Rats at diestrus, with intermediate levels of hormones, demonstrated no bias in strategy use, with $43 \%$ of the population using place and $57 \%$ using response. Unlike our previous report (Korol et al. 2004), none of these biases reached statistical significance with binomial tests $(P s>0.05)$. However, similar to prior results, cycle-related biases in strategy

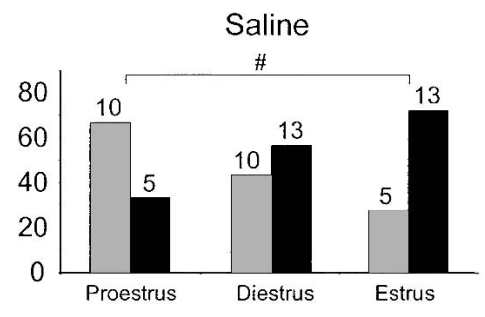

$\square$ place

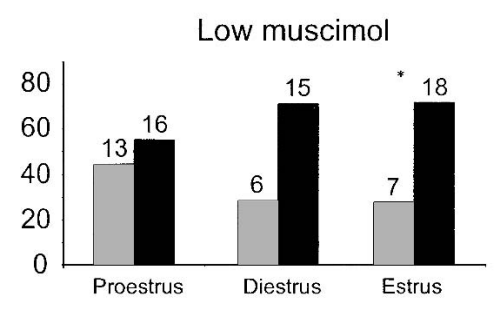

High muscimol

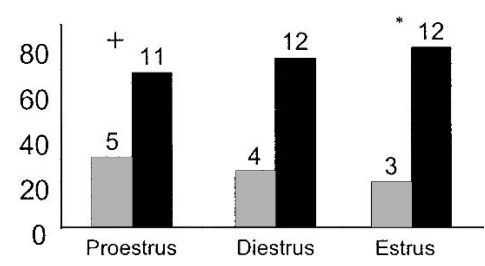

Figure 2. Strategy selection and the effects of muscimol treatment and estrous cycle stage. (Top) Strategy biases across the estrous cycle in salinetreated rats. Note that significant differences between groups appeared with proestrous rats using a place strategy and estrous rats using a response strategy. Diestrous rats demonstrated no strategy bias. (Middle, bottom) Low (middle) and high (bottom) muscimol treatment shifted strategy use toward response. ${ }^{*} P<0.05$ within group; $\# P<0.05$ between estrous cycle groups within treatment; $+P<0.05$ relative to saline controls. 
were significantly different between proestrous and estrous rats $\left(\chi_{[1,32]}^{2}=4.99, P<0.05\right)$, but not between diestrus rats and either proestrous $\left(\chi_{[1,38]}^{2}=2.84, P>0.05\right)$ or estrous $\left(\chi_{[1,40]}^{2}=1.07\right.$, $P>0.05$ ) rats (Fig. 2, top panel).

In general, muscimol treatment diminished the estrous cycle-related differences in strategy observed in saline-treated control rats, producing a general shift toward the use of response strategies at all stages (Fig. 2). The magnitude of the muscimol effect varied with estrous cycle as proestrous rats demonstrated the largest shift following muscimol treatment relative to saline controls, yet estrous rats demonstrated the most complete bias in strategy following muscimol treatment.

In proestrous rats, while treatment with low muscimol increased the proportion of rats using response strategies, from $33 \%$ in the saline group to $55 \%$ in the low muscimol group, the relative strategy use following low muscimol treatment did not reflect a significant bias $(z=0.37, P>0.05)$ and did not differ significantly from saline-treated rats $\left(\chi^{2}{ }_{[1,43]}=1.89, P>0.05\right)$. High muscimol administration to proestrous rats produced a shift in use of response over place strategies, a bias that in itself was not statistically significant or different from proestrous rats treated with the low muscimol dose $\left(\chi_{[1,45]}^{2}=0.79, P>0.05\right)$. However, high muscimol treatment to proestrous rats did significantly shift the place learning strategy bias observed in salinetreated proestrous rats to a response learning strategy bias $\left(\chi_{[1,30]}^{2}=3.89, P<0.05\right)$.

Strategy biases were observed in estrous rats following both low and high muscimol treatment $\left(P_{\mathrm{S}}<0.05\right)$, whereas the biases produced in diestrous rats did not reach significance $(P s>0.05$ low and high). However, neither the low nor the high muscimol doses produced significant differences from saline treatment in the diestrous (low: $\chi^{2}{ }_{[1,43]}=1.95, P>0.05$; high: $\chi_{[1,38]}^{2}=1.40$, $P>0.05$ ) and estrous (low: $\chi^{2}{ }_{[1,42]}=0.0002, P>0.05$; high: $\left.\chi^{2}{ }_{[1,31]}=0.84, P>0.05\right)$ cycle groups. This lack of muscimol effect relative to saline most likely results from the use of response strategies already present in saline-treated diestrous and estrous rats (Fig. 2, top panel).

When the effects of muscimol are viewed as a shift in strategy relative to control performance, approximately the same incremental treatment-related shift in the proportions of rats using place and response strategies occurred across proestrous and diestrous stages. For example, the low dose of muscimol to proestrous rats shifted them from control values of $67 \%$ place $/ 33 \%$ response to $45 \%$ place $/ 55 \%$ response, producing a pattern of results similar to control diestrous rats. Similarly, diestrous control rats displayed $43 \%$ place $/ 57 \%$ response and shift to $29 \%$ place/ $71 \%$ response following low muscimol treatment, producing a bias in strategy similar to that observed in control estrous rats (Fig. 2). In sum, low muscimol treatment led to a profile of strategy use in proestrous rats similar to that observed in diestrous rats, as well as strategy use in diestrous rats that looked like that seen in estrous rats. Furthermore, high muscimol treatment in proestrous rats produced a strategy bias similar to that observed in diestrous rats administered the low dose of muscimol and in estrous rats under saline conditions. Estrous rats had a bias to response under control conditions and a similar bias under low and high muscimol conditions.

\section{Effects of treatments on learning speed}

No differences in speed of learning were found across muscimol treatment groups regardless of estrous status and strategy used (main effect of treatment: $F_{[2,175]}=0.012, P>0.05$ ), with rats across all treatment groups reaching criterion of nine of 10 correct trials in 27 trials on average (Fig. 3, top panel). Similarly, trials to reach criterion were not different across estrous cycle
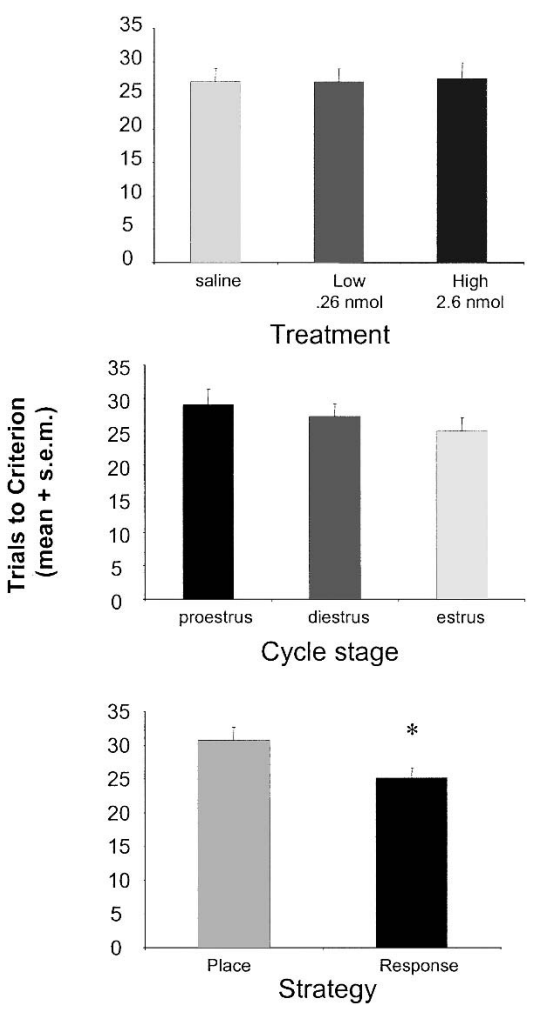

Figure 3. Main effects of treatment, estrous cycle stage, and strategy on learning speed measured as trials to reach criterion. (Top, middle) Neither treatment (top) nor estrous cycle stage (middle) affected learning speed. (Bottom) Data indicating that rats using a place strategy took significantly longer to learn than did rats that used a response strategy. $\star P<0.05$.

stage regardless of treatment group (main effect of estrous status: $F_{[2,175]}=0.936, P>0.05$ ) (Fig. 3 , middle panel). Interestingly, rats using response strategies $(n=115)$ solved the task significantly faster than did those using place strategies $(n=63)$ regardless of drug treatment or estrous cycle phase $\left(F_{[1,176]}=5.130, P>0.05\right)$ (Fig. 3, bottom panel), although the mean difference was small; mean trials to criterion were 25 for rats using response and 31 for rats using place. There was no significant interaction of estrous cycle and muscimol treatment on learning speed $\left(F_{[4,169]}=0.492\right.$, $P>0.05$ ) (data not shown). Furthermore, while significant effects of strategy on trials to criterion were observed, the effects of strategy on learning speed failed to interact significantly with effects of muscimol treatment $\left(F_{[2,172]}=0.379, P>0.05\right)$, estrous cycle stage $\left(F_{[2,172]}=1.073, P>0.05\right)$, or both $\left(F_{[4,160]}=0.409\right.$, $P>0.05$ ) (data not shown).

The differences in trials to criterion in rats using place and response strategies may be a result of hippocampal damage produced by cannula implantation. To test this, we examined performance on the T-maze task in unoperated rats. All methods were the same as those described previously except for the exclusion of cannula implantation and drug infusion. A two-way ANOVA assessing the effects of strategy and implantation status on trials to reach criterion revealed a main effect of strategy $\left(F_{[1,210]}=4.68, P<0.05\right)$ but no main effect of implantation status $\left(F_{[1,210]}=0.83, P>0.05\right)$ (data not shown). Both operated and unoperated rats using place strategies took significantly more trials to reach criterion than did rats using response strategies. Similar to results described above, unoperated rats using response strategies averaged 22 trials, whereas those using place strategies averaged 29 trials to reach criterion. No significant interaction

\section{Learning \& Memory}


between implantation status and strategy was observed for trials to criterion $\left(F_{[1,210]}=0.04, P>0.05\right)$.

\section{Effects of treatments on choice latency}

Choice latencies on the habituation trial ranged from 4-120 sec, on the first training trial from 1-63 sec, and on the probe trial from 1-24 sec (data not shown). A two-way ANOVA showed that latency on the habituation trial did not differ by muscimol treatment $\left(F_{[2,168]}=1.148, P>0.05\right)$ or estrous phase $\left(F_{[2,168]}=0.265\right.$, $P>0.05)$, and there was no estrous cycle by treatment interaction on habituation trial latency $\left(F_{[4,168]}=0.812, P>0.05\right)$. Both muscimol treatment and estrous phase failed to influence latency on the first training trial $\left(F_{[2,168]}=2.202, P>0.05 ; F_{[2,168]}=0.740\right.$, $P>0.05)$, with no interactions between these variables $\left(F_{[4,168]}=0.439, P>0.05\right)$. Probe trial latency also failed to differ by treatment $\left(F_{[2,169]}=0.742, P>0.05\right)$, estrous phase $\left(F_{[2,169]}=0.696\right.$, $P>0.05)$, or their interaction $\left(F_{[4,169]}=0.733, P>0.05\right)$.

Trial latencies for each rat across training were split into three groups to reflect latency during early, middle, and late training. Within each epoch, latencies for each rat were averaged. A repeated-measures ANOVA showed that latency decreased across training trials $\left(F_{[2,338]}=81.43, P<0.05\right)$, regardless of treatment $\left(F_{[4,338]}=1.91, P>0.05\right)$ and estrous phase $\left(F_{[4,338]}=1.29\right.$, $P>0.05)$. There was no treatment by estrous phase interaction on latency across training $\left(F_{[8,338]}=1.29, P>0.05\right)$.

\section{Discussion}

Microinjections of muscimol into the hippocampus led to the predominant use of a response strategy over other effective solutions such as the place strategy. This robust effect on strategy was dose dependent and varied across the estrous cycle, with rats at proestrus, i.e., those with high ovarian hormone profiles, demonstrating the largest overall shift in strategy following muscimol infusion into the hippocampus, reflecting perhaps an initial bias toward place in baseline conditions. Rats at estrus, while demonstrating a less dramatic effect of muscimol on strategy preferences compared with controls, exhibited the most complete bias toward the use of response strategies following muscimol treatment, again reflecting perhaps the preference toward response learning already present in control conditions. The similarity in trials to criterion across treatments indicates that muscimol promoted the use of an alternative strategy without producing deficits or enhancements in learning. This is the first demonstration that muscimol application to the hippocampus caused a shift in strategy use without modulating the speed of acquisition. In addition, fluctuations in hormone levels across the estrous cycle may influence cognitive strategy through a GABAergicdependent mechanism.

Infusions of muscimol into the dorsal hippocampus in male rats produce impairments in fear learning (Corcoran and Maren 2001; Rossato et al. 2004), working memory (Mao and Robinson 1998; Maruki et al. 2001), and spatial memory (Moser and Moser 1998a; Vianna et al. 2000). Because muscimol is a potent $\mathrm{GABA}_{\mathrm{A}}$ agonist, it is likely that hippocampal infusions of muscimol modulate learning through increased neural inhibition of the hippocampus. Pharmacological inactivation of the hippocampus with lidocaine, a reversible sodium channel blocker, produced similar changes in learning seen as decreased place learning ability (Chang and Gold 2003a), decreased place strategy use, and increased response strategy use on a dual solution T-maze (Packard and McGaugh 1996). If inactivation of the hippocampus with local anesthetics/sodium channel blockers such as lidocaine leads to the use of response solutions (Packard and McGaugh 1996; Chang and Gold, 2003a), then one might expect infusions of muscimol, a $\mathrm{GABA}_{\mathrm{A}}$ agonist, into the hippocampus to produce biases toward the use of response strategies. Our data align well with this prediction and suggest that inactivation of the hippocampus by muscimol diminishes the contribution of the hippocampus to learning and memory.

The possibility that our dose and volume of muscimol infusions reduced activity in hippocampus is supported by findings from electrophysiological measurement of unit activity. Recordings from several sites distal to muscimol infusions in the nucleus basalis magnocellularis and the thalamus revealed a significant decrease in spontaneous activity radiating as far as $3 \mathrm{~mm}$ from the injection site and lasting 10-120 min following infusions (Edeline et al. 2002). The time course and dispersion of the suppression of activity suggest that muscimol diffuses through tissue in a manner dependent on the initial concentration of muscimol and the properties of the tissue. While the volume and concentration used in the current study are comparable to levels used in some reports (Vianna et al. 2000), they are relatively low compared with other studies (Corcoran and Maren 2001; Zarrindast et al. 2002). However, concentrations of muscimol as low as 2 $\mathrm{mM}$, well below the $8 \mathrm{mM}$ used here for the high dose, were still effective in inhibiting spontaneous activity (Edeline et al. 2002); thus, we feel confident that adequate inactivation of hippocampal activity was produced with the high muscimol treatment. Similarly, relatively small volume lesions to the hippocampus may be sufficient to disrupt spatial memory. It has been suggested that the location or orientation rather than the extent of damage may determine the magnitude of spatial memory impairment (for review, see Moser and Moser 1998b; Steffenach et al. 2002).

\section{Implications for ovarian hormone interactions with GABA}

The results from our saline-treated groups replicate our previous findings showing a significant fluctuation in strategy use across the estrous cycle (Korol et al. 2004) with proestrous rats using place and estrous rats using response. Because measures of GABAergic function and inhibitory tone in the hippocampus fluctuate with different regimens of estradiol exposure (Murphy et al. 1998; Rudick and Woolley 2001), strategy biases across the cycle may reflect differences in inhibitory function in the hippocampus. Considerable evidence suggests that the hippocampus is relatively more excitable during proestrus when ovarian steroids are high (Terasawa and Timiras 1968) or when ovariectomized rats are treated with estrogen (Terasawa and Timiras 1968; Buterbaugh and Hudson 1991; Edwards et al. 1999). Perhaps the decrease in inhibitory tone at proestrus creates a heightened hippocampal system prepared to use place strategies to solve tasks (Fig. 4). In contrast, increased hippocampal inhibition during estrus may impede the use of hippocampus-sensitive strategies, permitting other strategies such as striatal-sensitive approaches to prevail, a finding shown in males to result following hippocampal inactivation (Packard and McGaugh 1996).

It is unclear whether the change in strategy use across the estrous cycle reflects changes in synthesis, release and/or receptor binding properties of GABA. Estrogen applied in vitro (Murphy et al. 1998) or in vivo (Rudick and Woolley 2001) down-regulates glutamic acid decarboxylase, the rate limiting enzyme for the synthesis of GABA, in a population of hippocampal interneurons that also stain positively for estrogen receptors (Hart et al. 2001; Su et al. 2001). Steady-state concentrations of GABA are stable throughout the day and across the estrous cycle in the medial septum and CA1 region of the hippocampus (Grattan et al. 1996). However, inhibitory postsynaptic currents in CA1 pyramidal cells decrease in magnitude and frequency $24 \mathrm{~h}$ after 


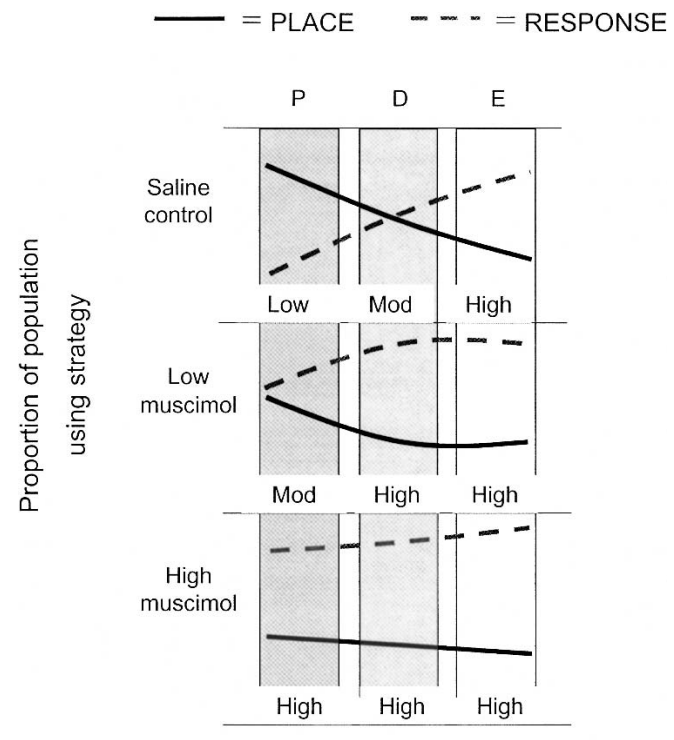

Theoretical level of hippocampal inhibition

Figure 4. Theoretical representation of the effects of estrous cycle and intrahippocampal muscimol on hippocampal inhibition and learning strategy. Graphs depict the relative use of place and response strategies at proestrus (P), diestrus (D), or estrus (E) under saline, low muscimol, and high muscimol. Theoretically, hormonal changes across the estrous cycle may act through the GABAergic system to change inhibitory tone in hippocampus and thus change strategy selection: The greater the inhibition, the more likely rats are to use a response strategy. A cycle-related shift in strategy bias is seen in saline controls, with proestrus rats using place and estrous rats using response. With increasing doses of muscimol, and presumably increasing levels of hippocampal inactivation (low, moderate, high), strategy biases shift toward the response strategy.

estrogen exposure in vivo (Rudick and Woolley 2001), suggesting decreased efficacy of GABA following estrogen exposure, an effect regulated in part by the presence of acetylcholine (Rudick et al., 2003). Despite the hormone-induced down-regulation of GABA function measured by changes in inhibitory postsynaptic currents (Murphy et al. 1998; Rudick and Woolley 2001; Rudick et al. 2003) and numbers of chloride ion channel receptors (Canonaco et al. 1993), estrogen has been shown to increase muscimol binding in the hippocampus (Canonaco et al. 1989; Schumacher et al. 1989). It is also thought that estrogen may shift $\mathrm{GABA}_{\mathrm{A}}$ receptors from low to high affinity (Schumacher et al. 1989). Together, the results suggest that estrogen, possibly along with progesterone, both decreases inhibition and leads to heightened sensitivity of hippocampal GABA system as a control mechanism for hyperexcitability that could otherwise lead to excitotoxicity (Goodman et al 1996; Azcoitia et al. 1999; Ciriza et al. 2004).

Examination of intrahippocampal muscimol effects on cognition points to possible mechanisms involving the regulation of inhibitory tone that underlie the strategy shift observed across the cycle (Fig. 4). When estrogen and progesterone levels are high, such as at proestrus, muscimol and other chloride ion ligands bind more potently to the $\mathrm{GABA}_{\mathrm{A}}$ receptor (Canonaco et al. 1989; Schumacher et al. 1989; Jussofie 1993), suggesting that muscimol would have a greater effect in proestrus, i.e., in a system that has lowered inhibitory tone. In support of this, we found that proestrous rats experienced the greatest strategy shift to response following muscimol treatment relative to control treatment. Saline-treated diestrous rats did not exhibit a strategy bias, perhaps a reflection of intermediate levels of ovarian steroids and thus relatively intermediate levels of inhibition com- pared with proestrous and estrous rats (Fig. 4). Muscimol treatment failed to produce a significant shift in strategy use in diestrous rats, likely the result of no strategy preferences in saline-treated rats. Previous reports suggest that the potency of muscimol is reduced at diestrus compared with proestrus (Canonaco et al. 1989; Schumacher et al. 1989; Jussofie 1993); however, the finding that muscimol treatment did produce an incremental shift to response strategy in diestrus rats similar to that observed in proestrous rats suggests that the efficacy of muscimol at diestrus is high enough to produce shifts in strategy. It is also possible, however, that for proestrous rats, a "ceiling effect" for the bias toward place in control conditions precluded our ability to measure an even larger shift following the low dose of muscimol.

Estrous rats maintained the same level of preference for a response learning strategy regardless of muscimol treatment. The lack of muscimol effect on strategy in estrous rats may reflect the possibility that estrous rats are more resistant to the shifting properties of muscimol given that hippocampal neurons are less sensitive to $\mathrm{GABA}_{\mathrm{A}}$ ligands at stages with low hormones (Canonaco et al. 1989; Schumacher et al. 1989; Jussofie 1993). Alternatively, but not mutually exclusively, effects of muscimol in estrous rats may have been shadowed by a "floor effect," in that estrous rats demonstrated a response bias in control conditions (Fig. 4) and we may be unable to detect further strategy shifts. It is also possible that the different effects of muscimol treatment on strategy use across the estrous cycle relate to differences in drug metabolism (for review, see Anthony and Berg 2002). To tease apart these possibilities, we are currently testing strategy shifts to place in rats at estrus following challenge with $\mathrm{GABA}_{\mathrm{A}}$ antagonists such as bicuculline.

Although effects of estrogen on hippocampal inhibition have been the focus of many recent reports, the likelihood that changes in progesterone contribute to the observed effects needs to be considered. Progesterone and some of its metabolites, shown to be high late in proestrus and early in estrus, enhance inhibition, perhaps balancing the excitation caused by estrogen (Terasawa and Timiras 1968; Herkes et al. 1993; Wilson and Biscardi 1997; Edwards et al. 1999) and interact with muscimol treatment (Czlonkowska et al. 2001). Therefore, if strategy shifts result from changes in GABA function/inhibitory tone, then we would expect a shift in the dose-response function for muscimol treatment plus high progesterone, e.g., in the late afternoon of proestrus or the early morning of estrus, with lower doses producing even greater shifts to response strategies. Because our rats were tested in the late morning to early afternoon, we are unable to attribute any of our findings specifically to progesterone.

Together the results suggest that hippocampal participation in learning is high at times of increased levels of circulating ovarian steroids such as during proestrus and low during periods of low hormone levels, such as at estrus, a finding supported by other reports (Fader et al. 1998; Gibbs et al. 1998; Bimonte and Denenberg 1999; Daniel and Dohanich 2001; Korol and Kolo 2002; Daniel and Lee 2004; Korol et al. 2004). Cyclic changes in GABA function related to the production, release, and/or binding properties may predispose rats to favor specific learning strategies over equally effective approaches.

\section{Implications for neural systems for learning and memory}

The task used in the current study can be solved by using two different effective strategies, place and response, that have been mapped onto the hippocampus and striatum, respectively (Packard and McGaugh 1996; Schroeder et al. 2002; Chang and Gold 2003a; Colombo et al. 2003). Our results support the idea that the hippocampus is involved in place learning and that differ-

\section{Learning \& Memory}


ences in patterns of hormones across the estrous cycle alter the relative participation of one neural system over another. Furthermore, we report that rats can shift from using the two strategies equally to using the hippocampal-insensitive response strategy when hippocampal inactivation occurs through $\mathrm{GABA}_{\mathrm{A}}$ activation, findings similar to those seen when lidocaine is used to inactivate the hippocampus (Packard and McGaugh 1996). The finding that no learning deficit was observed following muscimol treatment is likely a result of availability of an alternative memory system, perhaps one that relies on intact striatal function (Packard et al. 1989; McDonald and White 1993; for review, see White and McDonald 2002). Within this conceptual framework, it is possible that rats with hippocampal muscimol treatment would show enhanced performance on tasks requiring the use of response or cued strategies.

Unlike in previous studies (Korol et al. 2004), rats using response strategies solved the task faster than did those using place strategies regardless of treatment, estrous cycle stage, or cannula implantation. The learning speed difference between rats using place and rats using response strategies may result from the possibility that faster learners made a faster transition from place to response (Chang and Gold 2003b; C. Canal and P. Gold, pers. comm.), that the inclusion of a habituation trial facilitated response learning (Hironaka et al. 2001), or that distribution of the room cues in the current experiment favored response learning (Restle 1957; Cressant and Granon 2003).

As expected, choice latency decreased across training trials, a finding shown repeatedly in these and similar tasks (Korol and Kolo 2002; Korol et al. 2004). Importantly, no treatment or group differences in latencies were observed during the first two trials on the maze, suggesting that the behavioral response to the maze, including nonmnemonic features, was similar in all rats. Also as expected, treatment and estrous cycle stage did not affect latency across training, indicating that the groups had similar nonmnemonic behavioral responses to training. Choice latencies on the probe test were also not influenced by muscimol treatment or hormonal profile, the latter matching previous reports (Korol et al. 2004).

\section{Conclusions}

The results of this study support the well-established findings that the hippocampus is involved in the effective use of place learning strategies. Although pharmacological inactivation of the hippocampus caused rats to shift learning strategy, learning speed was not affected. The results replicate our previous reports demonstrating preferences for place strategies in proestrous rats and for response strategies in estrous rats. While muscimol treatment failed to change substantially the response strategy bias observed in estrous rats, muscimol treatment caused a cognitive shift from a place to a response strategy bias in proestrous rats. These findings lend further support for the interaction of estrogen and GABA and the possibility that changes in the hormonal state of the animal may produce neurochemical and functional states in specific brain structures that modulate learning and memory.

\section{Materials and Methods}

\section{Subjects}

One hundred seventy-eight 3-mo-old gonadally intact, virgin Sprague-Dawley female rats (Harlan, Indianapolis) were used. After arrival, rats were allowed 1 wk to adjust to the vivarium before experimental procedures began. Rats were individually housed, kept on a 12-h light/12-h dark cycle, and given food and water ad libitum until food restriction was initiated. Rats were randomly assigned to three different intrahippocampal treatment groups: saline controls, low dose of muscimol (LO), and high dose of muscimol (HI). Within the treatment groups, rats were further divided post hoc into estrous cycle groups (proestrus, estrus, and diestrus) based on vaginal cytology. Nine treatment groups were generated, reflecting three treatments (saline, LO, and HI) and three estrous cycle stages (proestrus, estrus, and diestrus). An unoperated group of rats similarly assessed by estrous cycle stage was also included.

All procedures were in accordance with institutional and federal guidelines for the care and use of animals in research.

\section{Cycle staging}

Vaginal cells were collected daily for at least $14 \mathrm{~d}$ to determine estrous cycle phase. A small, sterile swab (Fisher Scientific) was soaked in sterile saline. The swab was inserted into the vagina, and cells were extracted by gently rubbing the swab against the vaginal walls. Cells from the swab were wiped onto a clean slide, fixed with alcohol, and allowed to dry for later staining with hematoxylin and eosin. Estrous cycle stage was determined by using the guidelines by Long and Evans (1922). Rats with fewer than two complete 4- to 5-d estrous cycles were excluded from the study. Based on the cells taken on the day of training, rats were assigned to one of three estrous cycle stages: proestrus, estrus, or diestrus.

\section{Surgery}

At least 2 wk prior to training, rats were anesthetized with ketamine $(74 \mathrm{mg} / \mathrm{kg}) / x y l a z i n e ~(5 \mathrm{mg} / \mathrm{kg}$; intraperitoneally) and administered the nonsteroidal anti-inflammatory drug Rimadyl (5 mg/kg; subcutaneously). Under stereotaxic control and aseptic procedures, a 22-gauge guide cannula (Plastics One Inc.) aimed at the dorsal hippocampus ( $3.8 \mathrm{~mm}$ posterior to bregma, $2.5 \mathrm{~mm}$ lateral to midline, $2.0 \mathrm{~mm}$ ventral to dura) was implanted bilaterally in each rat. Four jeweler's screws were screwed into the skull, and dental acrylic was used to anchor the cannulae to the skull. To keep the guide cannulae patent, sterile dummy cannulae were inserted into the guide cannulae. Following surgery, bacitracin was applied to the wound, and $9 \mathrm{~mL}$ of sterile saline was injected subcutaneously. Dummy cannulae were cleaned twice a week with ethanol beginning 1 wk after surgery.

\section{Intrahippocampal infusions}

On the day of training, a 28-gauge injection needle was inserted into each guide cannula. Injection needles extended $1 \mathrm{~mm}$ beyond the guide cannulae. Rats received simultaneous bilateral infusions of $0.3 \mu \mathrm{L}$ of saline or an equivalent volume of muscimol (Sigma) into the dorsal hippocampus 20 min before training. Two concentrations of muscimol were used: $\mathrm{LO}=0.26 \mathrm{nmol}(0.1$ $\mu \mathrm{g} / \mu \mathrm{L} ; 0.87 \mathrm{mM})$ and $\mathrm{HI}=2.6 \mathrm{nmol}(1 \mu \mathrm{g} / \mu \mathrm{L} ; 8.7 \mathrm{mM})$. An infusion pump (Harvard Apparatus) delivered treatment at a flow rate of $0.3 \mu \mathrm{L} / \mathrm{min}$ for $1 \mathrm{~min}$. Injection needles were left in place for $1 \mathrm{~min}$ after the infusion to allow for sufficient diffusion away from the needle. After the injection needles were removed, the dummy cannulae were reinserted. Rats were then placed in a clean holding cage in the training room. Training began $20 \mathrm{~min}$ after injection needles were removed.

\section{Training apparatus and procedure}

One week before training, rats were food-restricted to $85 \%$ of their ad libitum body weight plus $5 \mathrm{~g}$ for normal growth. Rats were handled daily for 3 min beginning $1 \mathrm{wk}$ before training and given three Frosted Cheerios (General Mills), which later served as the food reward during training.

Rats were trained to find a food reward on a T-shaped maze in which using either a place (go to the same area of the room) or a response (turn L or R) strategy is successful (Fig. 5). The maze had four arms of black Plexiglas, with one of the four arms blocked to form a T throughout training. All arms of the maze were $45 \mathrm{~cm}$ long and $12.5 \mathrm{~cm}$ wide, with $7.5-\mathrm{cm}$-high walls. At the end of each arm was a receptacle that contained inaccessible Frosted Cheerio crumbs to eliminate the use of olfactory cues to 

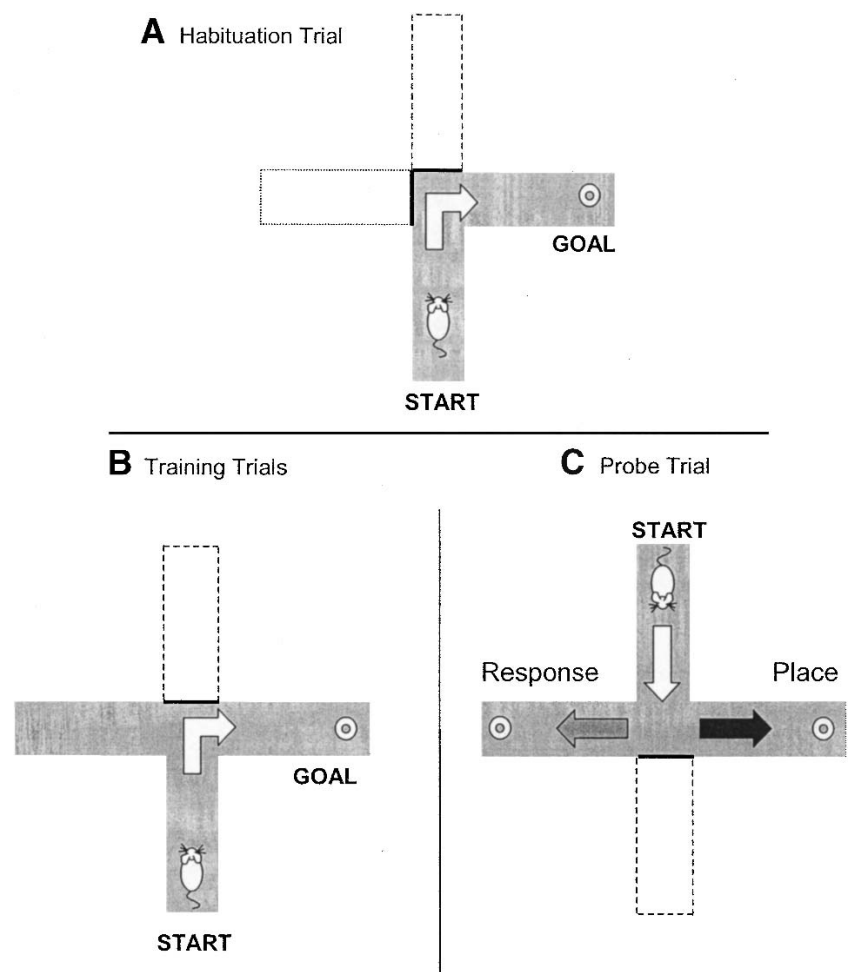

Figure 5. Rats were trained on a T-maze to locate food in a T-maze. In the habituation trial $(A)$, rats were forced to choose the correct arm. During the training trials $(B)$, the start and goal arms remained the same for each training trial. As rats learned to approach the arm that contained food, they could solve the maze by either making the same directional turn (e.g., right) or going to the same arm relative to extra-maze room cues. After reaching the learning criterion of nine of 10 correct trials, rats were given a probe trial (C). During the probe trial, the maze was rotated $180^{\circ}$ to assess learning strategy.

find the reward. One half of a Frosted Cheerio was placed in the receptacle in the goal arm such that it was accessible to the rat. Decoys (wood chips) were placed in the food receptacles at the end of the nongoal arms. Within the maze room, there were various two- and three-dimensional extramaze objects (posters, bookshelves, polygraph). A halogen lamp directed at the ceiling provided ambient room lighting. All rats were trained within $1 \mathrm{~d}$, 2-7 $\mathrm{h}$ prior to onset of the dark cycle.

Rats were randomly assigned to one of four training procedures such that the goal arm and direction that the rat turned to approach the goal arm were counterbalanced across all treatment and estrous cycle groups. Before training, a habituation trial was given in which two of the four arms were blocked, forming an L, such that only the start and goal arms were accessible (Fig. 5A). This was done to allow all rats to encounter the food reward on the first trial. All rats were allowed 2 min to enter the goal arm during the habituation trial. If the rat did not enter the goal arm within 2 min during the habituation trial, it was placed in the goal arm. Following the habituation trial, the rat was returned to the holding cage for an intertrial interval of $30 \mathrm{sec}$, after which training began. For the training trials, the maze was configured into a $T$ with the start and goal arms remaining in the same relative position throughout training (Fig. 5B). At the start of a training trial, the rat was placed in the start arm facing the choice point. The experimenter was always positioned behind the start arm. A choice was noted when the rat placed all four paws within the chosen arm. If no choice was made within 2 min (trial maximum), the rat was removed from the maze and placed in the holding cage for $30 \mathrm{sec}$ before another trial was begun. On trials in which the rat chose the goal arm, it was allowed to eat the reward and it was removed from the maze after 10 sec or after it turned to exit the goal arm. On trials in which the rat did not choose the goal arm, the rat was removed from the arm after 10 sec or after it turned to exit the arm. The intertrial interval was 30 sec, during which the rat was placed in the holding cage. During the intertrial interval, the maze was rebaited and rotated $90^{\circ}$ or $180^{\circ}$ using preset stops to prevent the use of intramaze cues.

After the learning criterion of nine of 10 correct choices was achieved, rats were given a probe test immediately after the intertrial interval to assess the learning strategy used during learning. During the probe test, the start arm was rotated $180^{\circ}$ relative to its position during training and both choice arms were baited (Fig. 5C). The probe trial was otherwise treated the same as other training trials, including the position of the experimenter behind the rotated start arm. Use of the place strategy was indicated when rats went to the arm that was in the same location of the room as it was during training. Use of the response strategy was indicated when rats turned in the same direction (left or right) as they did during training. Rats had a maximum of 2 min to enter an arm during the probe trial. Training was terminated if rats did not reach nine of 10 correct trials within 80 trials. For all trials, latency to choose (seconds) and correct or incorrect choice were recorded.

\section{Histology}

After training, rats were euthanized with an overdose of Nembutal $(75 \mathrm{mg} / \mathrm{kg})$, and $0.3 \mu \mathrm{L}$ of dye (Higgins fadeproof drawing ink, Faber-Castell Corporation) was injected into each hippocampus. Brains were removed and fixed in a $10 \%$ formalin solution for at

A
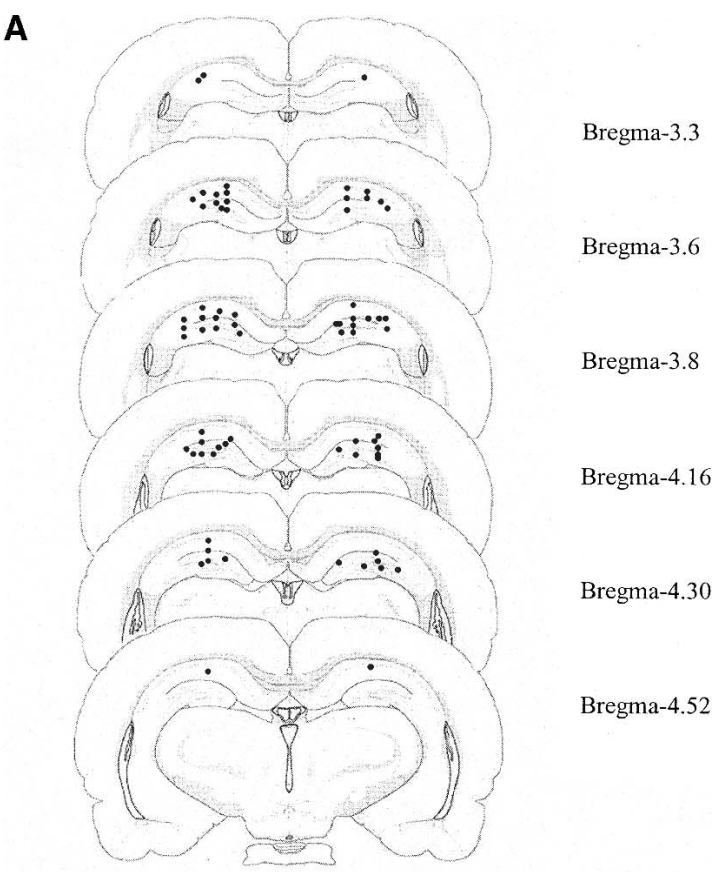

B

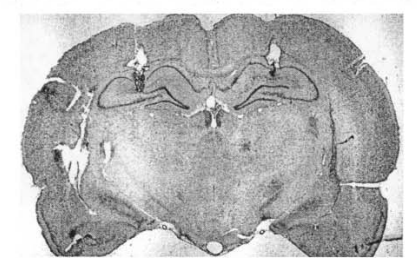

Figure 6. Cannula placements in the dorsal hippocampus. $(A)$ Distribution of cannula sites in the dorsal hippocampus ranged from 3.3-4.52 $\mathrm{mm}$ posterior to bregma. Dots can represent more than one rat. Graphic representations of coronal brain sections adapted from the rat brain atlas of Swanson (1998). (B) A representative brain section indicating the cannula tracts.

\section{Learning \& Memory}

www.learnmem.org 
least $1 \mathrm{wk}$ followed by placement into a $20 \%$ sucrose/PBS solution for $2 \mathrm{~d}$. Fifty-micrometer sections of the hippocampus were made with a cryostat at $-20^{\circ} \mathrm{C}$, mounted onto subbed slides and stained with cresyl violet. Guide cannula placements were observed at $40 \times$ using a light microscope. Figure $6 \mathrm{~A}$ illustrates cannula placements, and Figure $6 \mathrm{~B}$ shows a representative brain section. Rats with guide cannulae outside the hippocampus or with excessive damage to the hippocampus beyond the site of the cannula were eliminated from the study.

\section{Data analysis}

Within a treatment group, biases in strategy use, i.e., place versus response, were determined by using two-tailed binomial tests for both small and large $(N>25)$ samples, with $P=Q=0.5$. Differences in strategy use between treatment groups were made with pair-wise comparisons $\left(2 \times 2\right.$ contingency tables) using $\chi^{2}$ analyses to test for independence of samples. The effects of treatment, estrous cycle, and strategy, as well as their interactions on learning speed, were assessed with three-way ANOVAs on trials to criterion.

Because the number trials to criterion varied across rats, choice latency data for each rat across training were split into thirds to reflect latency during early, middle, and late training. Within those three groups, latency for each rat was averaged. Changes in choice latency across training were analyzed with two-way repeated-measures ANOVAs for effects of muscimol treatment and estrous cycle, using repeated measures on the early, middle, and late training groups.

For all analyses, the significance level $P$ was set at 0.05 .

\section{Acknowledgments}

This work was supported by National Science Foundation IBN0081061. We thank Niamh Condon for her technical help with this work and Dr. Edward Roy for his assistance with taking photomicrographs of cannula placements.

\section{References}

Anthony, M. and Berg, M.J. 2002. Biologic and molecular mechanisms for sex differences in pharmacokinetics, pharmacodynamics and pharmacogenetics: Part II. J. Womens Health Gend. Based Med. 11: $617-629$.

Azcoitia, I., Fernandez-Galaz, C., Sierra, A., and Garcia-Segura, L.M. 1999. Gonadal hormones affect neuronal vulnerability to excitotoxin-induced degeneration. J. Neurocytol. 28: 699-710.

Bimonte, H.A. and Denenberg, V.H. 1999. Estradiol facilitates performance as working memory load increases. Psychoneuroendocrinology 24: 161-173.

Buterbaugh, G.G. and Hudson, G.M. 1991. Estradiol replacement to female rats facilitates dorsal hippocampal but not ventral hippocampal kindled seizure acquisition. Exp. Neurol. 111: 55-64.

Canonaco, M., O'Connor, L.H., Pfaff, D.W., and McEwen, B.S. 1989. $\mathrm{GABA}_{\mathrm{A}}$ receptor level changes in female hamster forebrain following in vivo estrogen progesterone and benzodiazepine treatment: A quantitative autoradiography analysis. Exp. Brain Res. 75: 644-652.

Canonaco, M., Tavolaro, R., and Maggi, A. 1993. Steroid hormones and receptors of the $\mathrm{GABA}_{\mathrm{A}}$ supramolecular complex. Neuroendocrinology 57: 974-984.

Chang, Q. and Gold, P.E. 2003a. Intra-hippocampal lidocaine injections impair acquisition of a place task and facilitate acquisition of a response task in rats. Behav. Brain Res. 144: 19-24.

. 2003b. Switching from hippocampal to striatal memory systems during learning: Changes in patterns of acetylcholine release in rats. J. Neurosci. 23: 3001-3005.

Chesler, E.J. and Juraska, J.M. 2000. Acute administration of estrogen and progesterone impairs the acquisition of the spatial Morris water maze in ovariectomized rats. Horm. Behav. 38: 234-242.

Ciriza, I., Azcoitia, I., and Garcia-Segura, L.M. 2004. Reduced progesterone metabolites protect rat hippocampal neurons from kainic acid excitotoxicity in vivo. J. Neuroendocrinol. 16: 58-63.

Colombo, P.J., Brightwell, J.J., and Countryman, R.A. 2003. Cognitive strategy-specific increases in phosphorylated cAMP response element-binding protein and c-fos in the hippocampus and dorsal striatum. J. Neurosci. 23: 3547-3554.

Corcoran, K.A. and Maren, S. 2001. Hippocampal inactivation disrupts contextual retrieval of fear memory after reversal. J. Neurosci. 21: $1720-1726$.
Cressant, A. and Granon, S. 2003. Definition of a new maze paradigm for the study of spatial behavior in rats. Brain Res. Protoc. 12: $116-124$.

Czlonkowska, A.I., Krzascik, P., Sienkiewicz-Jaros, H., Siemiqtkowski, M., Szyndler, J., Maciejak, P., Bidzinski, A., and Plaznick, A. 2001. Rapid down-regulation of GABA-A receptors after pretreatment of mice with progesterone. Pol. J. Pharmacol. 53: 385-388.

Daniel, J.M. and Dohanich, G.P. 2001. Acetylcholine mediates the estrogen-induced increase in NMDA receptor binding in CA1 of the hippocampus and the associated improvement in working memory. J. Neurosci. 21: 6949-6956.

Daniel, J.M. and Lee, C.D. 2004. Estrogen replacement in ovariectomized rats affects strategy selection in the Morris water maze. Neurobiol. Learn. Mem. 82: 142-149.

Daniel, J.M., Fader, A.J., Spencer, A.L., and Dohanich, G.P. 1997. Estrogen enhances performance of female rats during acquisition of a radial arm maze. Horm. Behav. 32: 217-225.

Dohanich, G.P. 2002. Gonadal steroids, learning and memory. In Hormones, brain and behavior (eds. D.W. Pfaff et al.), pp. 265-327. Academic Press, San Diego, CA.

Edeline, J.M., Hars, B., Hennevin, E., and Cotillon, N. 2002. Muscimol diffusion after intracerebral microinjections: A reevaluation based on electrophysiological and autoradiographic quantifications. Neurobiol. Learn. Mem. 78: 100-124.

Edwards, H.E., Burnham, W.M., Mendonca, A., Bowlby, D.A., and MacLusky, N.J. 1999. Steroid hormones affect limbic after discharge thresholds and kindling rates in adult female rats. Brain Res. 838: $136-150$.

Fader, A.J., Hendricson, A.W., and Dohanich, G.P. 1998. Estrogen improves performance of reinforced T-maze alternation and prevents the amnestic effects of scopolamine administered systemically or intrahippocampally. Neurobiol. Learn. Mem. 69: 225-240.

Frye, C.A. 1995. Estrus-associated decrements in water maze task are limited to acquisition. Physiol. Behav. 57: 5-14.

Galea, L.A.M., Kavaliers, M., Ossenkopp, K.P., and Hampson, E. 1995. Gonadal hormone levels and spatial learning performance in the Morris water maze in male and female meadow voles, Microtus pennsylvanicus. Horm. Behav. 29: 106-125.

Galea, L.A.M., Lee, T.T.-Y., Kostaras, X., Sidhu, J.A., and Barr, A.M. 2002. High levels of estradiol impair spatial performance in the Morris water maze and increase 'depressive-like' behaviors in the female meadow vole. Physiol. Behav. 77: 217-225.

Gee, K.W. 1988. Steroid modulation of the GABA/benzodiazepine receptor-linked chloride ionophore. Mol. Neurobiol. 2: 291-317.

Gibbs, R.B., Burke, A.M., and Johnson, D.A. 1998. Estrogen replacement attenuates effects of scopolamine and lorazepam on memory acquisition and retention. Horm. Behav. 34: 112-125.

Gibbs, R.B., Gabor, R., Cox, R., and Johnson, D.A. 2004. Effects of raloxifene and estradiol on hippocampal acetylcholine release and spatial learning in the rat. Psychoneuroendocrinology 29: 741-748.

Goodman, Y., Bruce, A.J., Cheng, B., and Mattson, M.P. 1996. Estrogens attenuate and corticosterone exacerbates excitotoxicity, oxidative injury, and amyloid $\beta$-peptide toxicity in hippocampal neurons. J. Neurochem. 66: 1836-1844.

Grattan, D.R., Rocca, M.S., Strauss, K.I., Sagrillo, C.A., Selmanoff, M., and McCarthy, M.M. 1996. GABAergic neuronal activity and mRNA levels for both forms of glutamic acid decarboxylase $\left(\mathrm{GAD}_{65}\right.$ and $\mathrm{GAD}_{67}$ ) are reduced in the diagonal band of Broca during the afternoon of proestrus. Brain Res. 733: 46-55.

Hart, S.A., Patton, J.D., and Woolley, C.S. 2001. Quantitative analysis of $\mathrm{ER} \alpha$ and GAD colocalization in the hippocampus of the adult female rat. J. Comp. Neurol. 440: 144-155.

Herkes, G.K., Eadie, M.J., Sharbrough, F., and Moyer, T. 1993. Patterns of seizure occurrence in catamenial epilepsy. Epilepsy Res. 15: 47-52.

Hironaka, N., Tanaka, K., Izaki, Y., Hori, K., and Nomura, M. 2001. Memory-related acetylcholine efflux from rat prefrontal cortex and hippocampus: A microdialysis study. Brain Res. 901: 143-150.

Holscher, C. 2003. Time, space and hippocampal functions. Rev. Neurosci. 14: 253-284.

Johnson, C.T., Olton, D.S., Gage, F.H., and Jenko, P.G. 1977. Damage to hippocampus and hippocampal connections: Effects on DRL and spontaneous alternation. J. Comp. Physiol. Psychol. 91: 508-522.

Jussofie, A. 1993. Brain area specific differences in the effects of neuroactive steroids on the GABAA receptor complexes following acute treatment with anaesthetically active steroids. Acta Endocrinol. 129: $480-485$

Kawata, M. 1995. Roles of steroid hormones and their receptors in structural organization in the nervous system. Neurosci. Res. 24: 1-46.

Korol, D.L. and Kolo, L.L. 2002. Estrogen-induced changes in place and response learning in young adult female rats. Behav. Neurosci. 116: $411-420$. 
Korol, D.L. and Manning, C.A. 2001. Effects of estrogen on cognition: Implications for menopause. In Animal research and human health: Advancing human welfare through behavioral science (eds. M.E. Carroll and J.B. Overmier), pp. 305-322. American Psychological Association, Washington, D.C.

Korol, D.L., Malin, E.L., Borden, K.A., Busby, R.A., and Couper-Leo, J.M. 2004. Shifts in preferred learning strategy across the estrous cycle in young female rats. Horm. Behav. 45: 330-338.

Lalonde, R. 2002. The neurobiological basis of spontaneous alternation. Neurosci. Biobehav. Rev. 26: 91-104.

Long, J.A. and Evans, H.M. 1922. The oestrous cycle in the rat and its associated phenomena. Mem. Univ. Calif. 6: 1-148.

Luine, V.N., Jacome, L.F., and MacLusky, N.J. 2003. Rapid enhancement of visual and place memory by estrogens in rats. Endocrinology 144: $2836-2844$

Mao, J.B. and Robinson, J.K. 1998. Microinjection of GABA-A agonist muscimol into the dorsal but not the ventral hippocampus impairs non-mnemonic measures of delayed non-matching-to-position performance in rats. Brain Res. 784: 139-147.

Maruki, K., Izaki, Y., Hori, K., Nomura, M., and Yamauchi, T. 2001. Effects of rat ventral and dorsal hippocampus temporal inactivation on delayed alternation task. Brain Res. 895: 273-276.

McDonald, R.J. and White, N.M. 1993. A triple dissociation of memory systems: Hippocampus, amygdala and dorsal striatum. Behav. Neurosci. 107: 371-388.

Mickley, G.A., Ferguson, J.L., Nemeth, T.J., Mulvihill, M.A., and Alderks, C.E. 1989. Spontaneous perseverative turning in rats with radiation-induced hippocampal damage. Behav. Neurosci. 103: $722-730$.

Moser, M.B. and Moser, E.I. 1998a. Distributed encoding and retrieval of spatial memory in the hippocampus. J. Neurosci. 18: 7537-7542. . 1998b. Functional differentiation in the hippocampus. Hippocampus 8: 608-619.

Moser, E., Moser, M.B., and Andersen, P. 1993. Spatial learning impairment parallels the magnitude of dorsal hippocampal lesions, but is hardly present following ventral lesions. J. Neurosci. 13: $3916-3925$.

Murphy, D.D., Cole, N.B., Greenberger, V., and Segal, M. 1998. Estradiol increases dendritic spine density by reducing GABA neurotransmission in hippocampal neurons. J. Neurosci. 18: 2550-2559.

Packard, M.G. 1999. Glutamate infused posttraining into the hippocampus or caudate-putamen differentially strengthens place and response learning. Proc. Natl. Acad. Sci. 96: 12881-12886.

Packard, M.G. and McGaugh, J.L. 1996. Inactivation of hippocampus or caudate nucleus with lidocaine differentially affects expression of place and response learning. Neurobiol. Learn. Mem. 65: 65-72.

Packard, M.G. and Teather, L.A. 1997. Posttraining estradiol injections enhance memory in ovariectomized rats: Cholinergic blockade and synergism. Neurobiol. Learn. Mem. 6: 172-188.

Packard, M.G., Hirsh, R., and White, N.M. 1989. Differential effects of fornix and caudate nucleus lesions on two radial arm maze tasks: Evidence for multiple memory systems. J. Neurosci. 9: 1465-1472.

Pearce, J.M., Roberts, A.D., and Good, M. 1998. Hippocampal lesions disrupt navigation based on cognitive maps but not heading vectors. Nature 396: 75-77.

Poldrack, R.A. and Packard, M.G. 2003. Competition among multiple memory systems: Converging evidence from animal and human brain studies. Neuropsychologia 41: 245-251.

Ragozzino, M.E., Pal, S.N., Unick, K., Stefani, M.R., and Gold, P.E. 1998. Modulation of hippocampal acetylcholine release and spontaneous alternation scores by intrahippocampal glucose injections. $J$. Neurosci. 18: 1595-1601.
Restle, F. 1957. Discrimination of cues in mazes: A resolution of the "place-vs.-response" question. Psychol. Rev. 64: 217-228.

Rossato, J.I., Bonini, J.S., Coitinho, A.S., Vianna, M.R., Medina, J.H., Cammarota, M., and Izquierdo, I. 2004. Retrograde amnesia induced by drugs acting on different molecular systems. Behav. Neurosci. 118: $563-568$.

Rudick, C.N. and Woolley, C.S. 2001. Estrogen regulates functional inhibition of hippocampal CA1 pyramidal cells in the adult female rat. J. Neurosci. 21: 6532-6543.

Rudick, C.N., Gibbs, R.B., and Woolley, C.S. 2003. A role for the basal forebrain cholinergic system in estrogen-induced disinhibition of hippocampal pyramidal cells. J. Neurosci. 32: 4479-4490.

Schroeder, J.P., Wingard, J.C., and Packard, M.G. 2002. Post-training reversible inactivation of hippocampus reveals interference between memory systems. Hippocampus 12: 280-284.

Schumacher, M., Coirini, H., and McEwen, B.S. 1989. Regulation of the high-affinity $\mathrm{GABA}_{\mathrm{A}}$ receptors in the dorsal hippocampus by estradiol and progesterone. Brain Res. 487: 178-183.

Steffenach, H., Sloviter, R.S., Moser, E.I., and Moser, M. 2002. Impaired retention of spatial memory after transection of longitudinally oriented axons of hippocampal CA3 pyramidal cells. Proc. Natl. Acad. Sci. 99: 3194-3198.

Su, J., Qiu, J., Zhong, Y., Li, X., Wang, J., and Chen, Y. 2001. Expression of estrogen receptor (ER)- $\alpha$ and $-\beta$ immunoreactivity in hippocampal cell cultures with special attention to GABAergic neurons. J. Neurosci. Res. 65: 396-402.

Swanson, L.W. 1998. Brain maps: Structure of the rat brain, 2 nd ed. Elsevier Science B.V., St. Louis, MO.

Terasawa, E. and Timiras, P.S. 1968. Electrical activity during the estrous cycle of the rat: Cyclic changes in limbic structures. Endocrinology 83: $207-216$.

Thomas, D.L., McElroy, M.W., and Korol, D.L. 2001. Learning strategy in the female rat shifts with chronic estradiol deprivation and replacement. Soc. Neurosci. Abstracts 27: 534.2.

Turner, D.M., Ransom, R.W., Yang, J.S., and Olsen, R.W. 1989. Steroid anesthetics and naturally occurring analogs modulate the $\gamma$-aminobutyric acid receptor complex at a site distinct from barbiturates. J. Pharmacol. Exp. Ther. 248: 960-966.

Vianna, M.R., Alonso, M., Viola, H., Quevedo, J., de Paris, F., Furman, M., de Stein, M.L., Medina, J.H., and Izqierdo, I. 2000. Role of hippocampal signaling pathways in long-term memory formation of a nonassociative learning task in the rat. Learn. Mem. 7: 333-340.

Walker, D.L. and Gold, P.E. 1994. Intrahippocampal administration of both the D- and the L-isomers of AP5 disrupt spontaneous alternation behavior and evoked potentials. Behav. Neural Biol. 62: $151-162$.

Warren, S.G. and Juraska, J.M. 1997. Spatial and nonspatial learning across the rat estrous cycle. Behav. Neurosci. 111: 259-266.

White, N.M. and McDonald, R.J. 2002. Multiple parallel memory systems in the brain of the rat. Neurobiol. Learn. Mem. 77: 125-184.

Wilson, M.A. and Biscardi, R. 1997. Influence of gender and brain region on neurosteroid modulation of GABA response in rats. Life Sci. 60: 1679-1691.

Zarrindast, M.R., Bakhsha, A., Rostami, P., and Shafaghi, B. 2002. Effects of intrahippocampal injection of GABAergic drugs on memory retention of passive avoidance learning in rats. J. Psychopharmacol. 16: 313-319.

Received September 10, 2004; accepted in revised form January 4, 2005. 


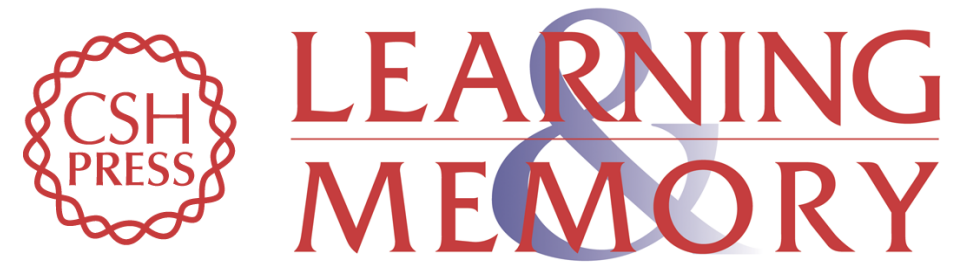

\section{Intrahippocampal muscimol shifts learning strategy in gonadally intact young adult female rats}

Molly W. McElroy and Donna L. Korol

Learn. Mem. 2005, 12:

Access the most recent version at doi:10.1101//m.86205

References This article cites 71 articles, 13 of which can be accessed free at:

http://learnmem.cshlp.org/content/12/2/150.full.html\#ref-list-1

License

Email Alerting Receive free email alerts when new articles cite this article - sign up in the box at the Service top right corner of the article or click here. 